\title{
LONG-TERM EFFECTS OF EXCISION OF THE RADIAL HEAD IN RHEUMATOID ARTHRITIS
}

\author{
L. A. RYMASZEWSKI, I. MACKAY, A. A. AMIS, J. H. MILlER
}

From the Accident and Orthopaedic Department, Glasgow Royal Infirmary

\begin{abstract}
The effects of synovectomy and excision of the radial head in $\mathbf{4 0}$ elbows affected by rheumatoid arthritis have been assessed. In contrast with many reports indicating minimal side-effects of this procedure, a common pattern of deterioration from what was often a satisfactory initial result has been demonstrated. A biomechanical theory of one of the factors responsible for failure has been put forward and the importance of conserving or replacing the radial head emphasised.
\end{abstract}

Over the last 50 years synovectomy of the elbow joint has become increasingly recognised as a safe, reliable method of relieving pain and thereby improving function (Swett 1929; Marmor 1972). In addition, most authors recommend excision of the radial head, especially in late cases with scanty synovium and marked degenerative changes in the radiohumeral compartment (Inglis, Ranawat and Straub 1971; Porter, Richardson and Vainio 1974). Taylor, Mukerjea and Rana (1976) considered that the latter procedure probably contributed more to the relief of pain than the synovectomy. Furthermore, excising the radial head provides good access for a more complete synovectomy through a single lateral incision. This avoids the trauma of an additional medial exposure, which may delay mobilisation and increase the chances of stiffness (Torgerson and Leach 1970; Stein, Dickson and Bentley 1975). Improvements in the range of movement after excising the radial head may be due not only to the relief of painful crepitus, but occasionally also to the removal of a mechanical block caused by a subluxated or deformed radial head (Brattström and $\mathrm{Al}$ Khudairy 1975).

Biomechanical evidence suggests the possibility that excision of the radial head may have adverse effects (Amis et al. 1979a), such as proximal migration of the radius, or valgus deformity and traction lesions of the medial soft tissues. Although there is evidence of such effects in post-traumatic cases (McDougall and White 1957; Taylor and O'Connor 1964) there is little published

L. A. Rymaszewski, FRCS, FRCS Ed, Registrar

I. Mackay, FRCS Glas, FRCS Ed(Orth), Senior Registrar

J. H. Miller, FRCS Glas, FRCS Ed, Consultant

Accident and Orthopaedic Division, Glasgow Royal Infirmary, Glasgow G4 0SF, Scotland.

A. A. Amis, BSc, PhD. Lecturer in Mechanical Engineering

Department of Biomechanics, Imperial College of Science and

Technology, Exhibition Road, London SW7 2BX, England.

Request for reprints should be sent to Mr L. Rymaszewski.

(C) 1984 British Editorial Society of Bone and Joint Surgery $0301-620 \mathrm{X} / 84 / 1001 \$ 2.00$ on the subject. This may be because of the short followup period in most published series but more probably because it is more difficult to delineate the pathology in limbs with polyarticular degeneration and extensive softtissue involvement, than it is in post-traumatic cases where the lesion is more localised.

The main purpose of this present study was, therefore, to investigate the long-term effects of excision of the radial head on the rheumatoid elbow.

\section{MATERIALS AND METHODS}

Synovectomy and radial head excision were performed on 52 elbows in 48 patients at Canniesburn Hospital, Glasgow, between 1972 and 1980. All these patients were asked to attend a special review clinic held by the authors, none of whom had been involved in the original treatment. Thirty-five patients who had 38 elbows operated on, together with a further two patients treated elsewhere attended, making a total of 40 elbows in 37 patients available for study. Each patient was assessed, subjective data being obtained via a questionnaire. Clinical examination of the elbows, wrists and hands was carried out and routine radiographs of the elbows and wrists were obtained. Follow-up after operation averaged six years, ranging from 2 to 15 years.

Of those who could not attend four patients had died, five were too ill to travel and a further four could not be traced. These patients were not included because we felt that the clinical records and radiographs did not yield sufficient information for accurate assessment.

There were 32 women and five men aged between 33 and 72 years (average 56 years). All but two patients had classical features of rheumatoid arthritis, 32 being seropositive. Most patients had been or were still receiving gold, penicillamine or steriods, an indication of the severity of their disease. The duration of the rheumatoid arthritis was 8 to 43 years (average 19 years); it had affected the elbow for 3 to 40 years (average 12 
years). Only one patient had not undergone another operation for rheumatoid arthritis, the average being three other operations per patient (range from none to 11). These other operations were almost evenly distributed between the upper and lower limbs, including 35 replacement arthroplasties of the hip or knee. Three elbows had been operated on twice because of an unsatisfactory initial result and two patients had each had three operations.

Silastic sheeting, $2 \mathrm{~mm}$ in thickness, had been interposed at the time of operation in 15 of the elbows. This sheeting tended to become detached and to fragment, displacing into a recess of the elbow joint. As this procedure was not thought to affect the stability of the joint, these 15 elbows were included in the series.

A lateral Kocher type of approach had been used in all but two cases. The ulnar nerve had been transposed in only two elbows, one at the time of operation, the other two years after operation.

\section{RESULTS}

Pain and tenderness. Success of the operation largely depends on the relief of pain. Pre-operative pain had often been generalised, tending to be greatest in the lateral compartment. However, we found that the majority of patients with painful elbows at review localised their symptoms to the medial side of the joint.

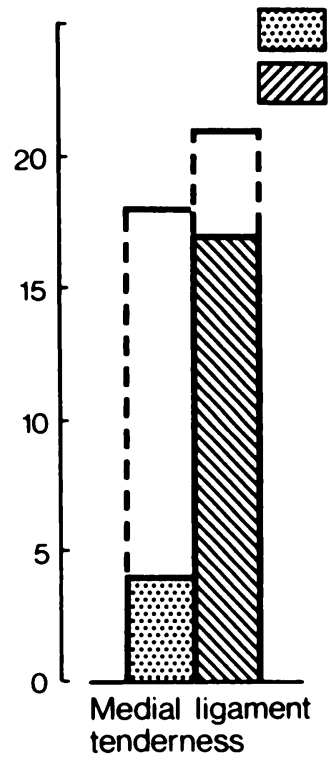

Pleased

Displeased/Deteriorating

Fig. 1

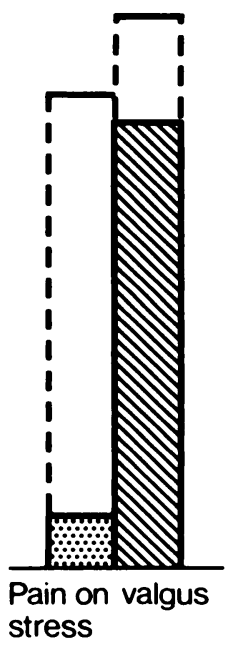

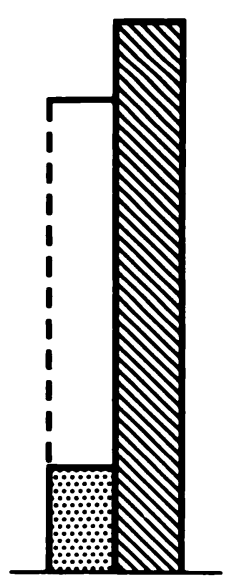

Painful/could not push up out of a chair
Stability and patients' assessment.

With regard to 18 of the 40 elbows, the patients stated that they were very pleased with the result of the operation; they had relief of pain and often subsequent improvement in function. In 12 elbows there had been either no relief or actual worsening of pain. In the remaining 10 elbows, initially good pain relief was tempered by later deterioration; four of these patients still considered the operation to have been worthwhile since the deterioration had not occurred till an average of five years later. In contrast, the other six patients in this group had recurrence of pain on average two-and-ahalf years later and rated the operation as unsuccessful. In one displeased patient the elbow had fused spontaneously and hence was excluded from assessment.

The clinical features of 18 elbows with a good result could therefore be compared with those of 21 painful or deteriorating joints. In the pleased group four patients had medial ligament tenderness and two had pain on valgus stress; this compared with 17 patients with these signs in the displeased or deteriorating groups (Fig. 1). In the latter group, all the patients either could not push themselves up out of a chair or had pain in doing so; only four patients in the pleased group complained of this.

Table I. Stability and assessment

\begin{tabular}{|lll|}
\hline & Pleased & $\begin{array}{l}\text { Displeased or } \\
\text { deteriorating }\end{array}$ \\
\hline Stable & 13 & 4 \\
Unstable & 5 & 17 \\
\hline
\end{tabular}

Stability. In the group of patients who were pleased with the operation, 13 of the elbows were considered to be stable, or had only slight varus/valgus instability, and only five were found to be markedly unstable. In contrast, in the group who were displeased with the result, 17 of the elbows were assessed as unstable and only four as stable joints (Table I).

Movements. The average amount of flexion was from 39 to 132 degrees, the range being from 5 to 65 degrees of extension and from 105 to 150 degrees of flexion; hence the disease process had limited extension to a much greater degree than flexion (Amis et al. 1982). The average amount of pronation and supination was 75 degrees in each direction with a range of 20 to 100 degrees of pronation and 15 to 110 degrees of supination. Unfortunately, not enough pre-operative data were available to compare pre-operative and postoperative movements, although 21 patients felt that the range of movement (of 22 elbows) had been improved.

Silastic sheeting. Eight patients in whom Silastic sheeting had been used had elbows which were free of pain; seven had painful elbows. The insertion of Silastic did not significantly affect the degree of pain relief, the range of movement or the stability.

The wrist. Three patients stated that their wrists had become worse after the operation. However, evaluation of the effect of radial head excision on the wrist was extremely difficult since wrist involvement by rheumatoid disease was present in almost all cases; 15 ipsilateral wrists had been operated on and five had developed a bony or fibrous ankylosis. 


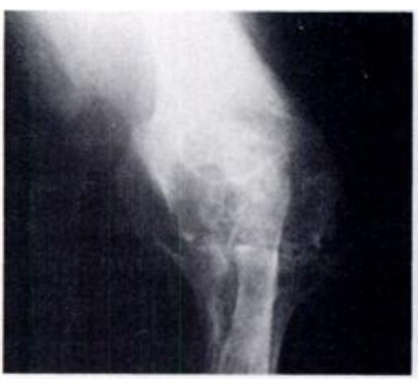

Fig. 2

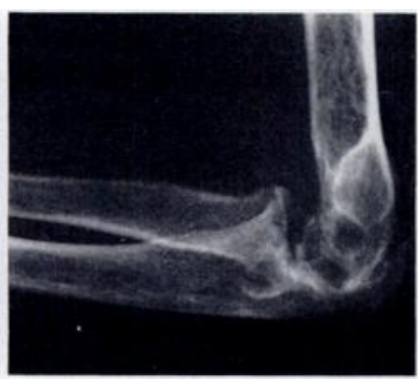

Fig. 3

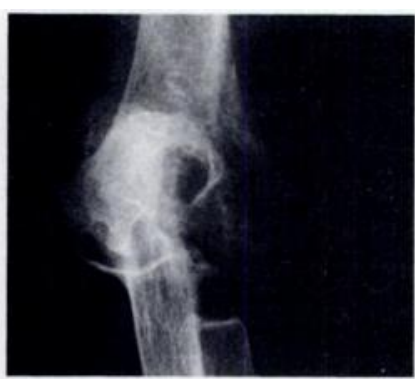

Fig. 4

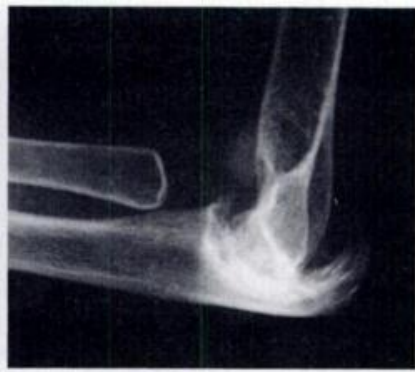

Fig. 5

Figures 2 and 3 - The appearance before operation. Figures 4 and 5 -At review six years later. Note the progressive degenerative change, the malalignment of the radius on the capitellum and the fragmented Silastic sheet anterior to the humerus.

The ulnar nerve. The wrists and hands of most patients had been involved by the disease, so that symptoms and signs which could be attributed exclusively to ulnar nerve involvement were difficult to demonstrate. Furthermore, several patients had cervical spine involvement, including one who had had a cervical spine fusion performed four years previously. As noted earlier, it had been found necessary to decompress the ulnar nerve in only two cases.

The carrying angle. It proved impossible to measure the carrying angle accurately on either clinical or radiological examination due to the marked flexion contracture present in almost all the elbows (Amis and Miller 1982).

Radiographs. In common with other reported series we found that the radiological appearances correlated poorly with the clinical results; nevertheless, several observations could be made. In no case where pre-operative films were available for comparison was there any improvement in the radiological grading (Steinbrocker, Traeger and Batterman 1949) of the elbows after operation; usually further degenerative changes had developed. Thirty-seven of the 40 elbows were in Grade III or IV, an indication of the extent of the disease (Table II). Malalignment of the radius on the capitellum was a frequent finding, presumably due to soft-tissue contracture secondary to muscle pull (Howard 1960). Thirty-four elbows were judged to have medial displacement of the radius towards the ulna, usually accompanied by anterior malalignment to a lesser degree; in several instances a radical resection of the radial head and neck had been carried out (Figs 2 to 5 ).

\section{DISCUSSION}

It is very difficult to evaluate the function of a single joint in the upper limb of a patient suffering from a polyarticular disease. In common with other series, we have used the simplest criterion of success - the patient's own degree of satisfaction. Our initial assessment of 28 good results out of 40 elbows ( 70 per cent) is similar to the success rate of other studies (71 per cent satisfactory in the series reported by Porter et al. in 1974, and 72 per cent in the series reported by Stein et al. in 1975). Although Porter et al. noted a tendency towards more unsatisfactory results after three years, both Copeland and Taylor (1979) and Marmor (1972) stated that deterioration seemed not to occur with the passage of time. In contrast, our work suggests that the initial benefits of the operation are not maintained consistently; less than half the patients ( 45 per cent) were pleased with the result at review.

The reasons for dissatisfaction after synovectomy and radial head excision in the rheumatoid elbow do not seem to have been closely studied by previous authors. Continuing pain may be due to synovitis with progressive articular erosions, to secondary osteoarthritis, or to traction lesions of soft tissues. Mechanical loading, whether in carrying out everyday tasks or in using sticks or crutches, may exacerbate the symptoms. Most of the displeased patients in our study had a common pattern of medial tenderness and pain on valgus stress, clinical findings not highlighted in previously published series.

Table II. Radiographic grading

\begin{tabular}{|ll|}
\hline Grade & Number of elbows \\
\hline 0 & 0 \\
I & 2 \\
II & 1 \\
III & 18 \\
IV & 19 \\
\hline
\end{tabular}

These findings can be interpreted as being due to recurrent synovitis, as described by Laine and Vainio (1969), 52 per cent of whose patients had occasional or constant pain at the medial side of the elbow. An indication that the rheumatoid process itself was relatively quiescent in our group was that only six of the 37 patients were still receiving gold, penicillamine or steriods when reviewed. Further, as only three patients were judged to have a mild synovitis, this factor was considered not to be a major cause of pain.

Undoubtedly, as most of our patients showed considerable degenerative changes on radiography, the pain could be attributed to progressive articular damage and superimposed osteoarthritis. However, in most series, including our own, it has been found that 


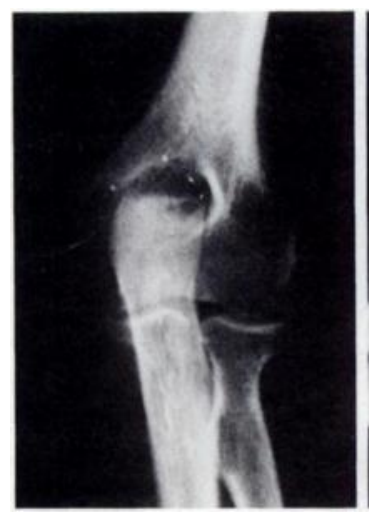

Fig. 6

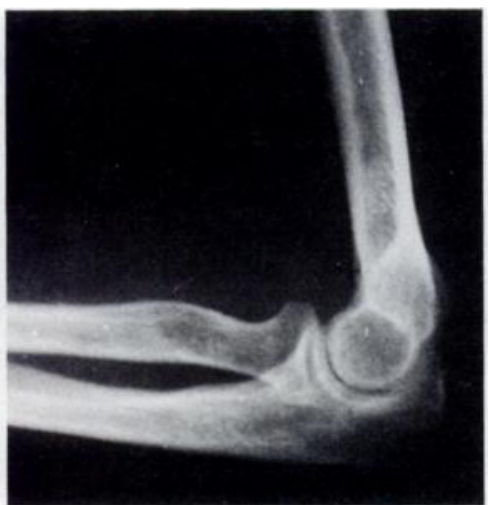

Fig. 7

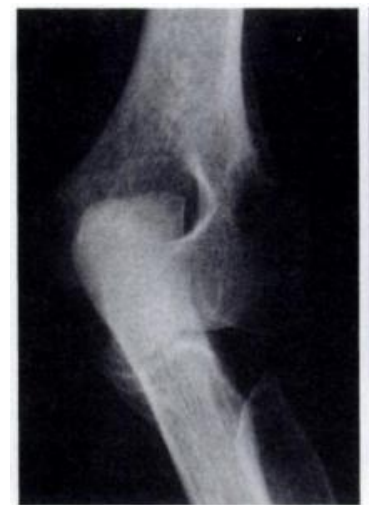

Fig. 8

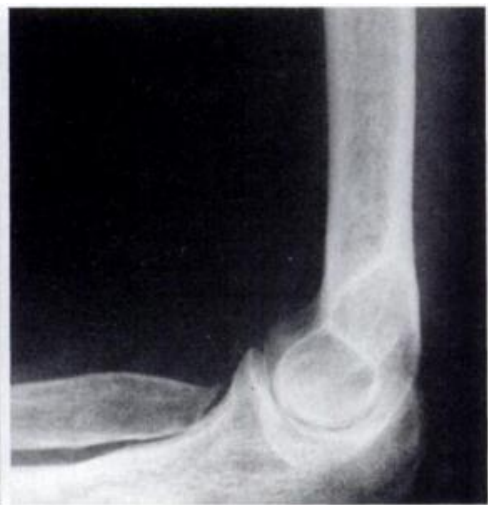

Fig. 9

Figures 6 and 7 -Pre-operative radiographs: after operation this patient initially had a good result but two years later the elbow deteriorated and pain developed on the medial side. Figures 8 and 9-The radiographs at review show an increased carrying angle; in the absence of erosive or degenerative changes this suggests that a traction lesion of the medial ligament was responsible for her pain.

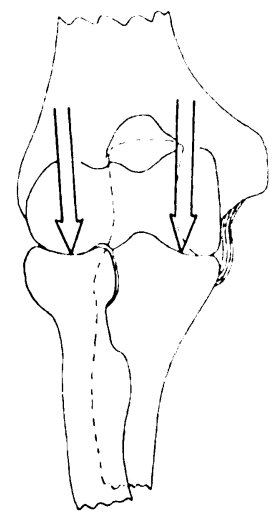

Fig. 10

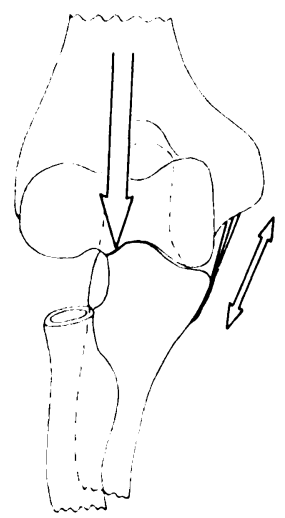

Fig. 11
Figure 10-.- The normal forearm bones are in equilibrium against the humerus during flexion, and there is no collateral ligament tension. Figure 11 -After radial head excision forces concentrate on the lateral edge of coronoid process. Medial ligament tension prevents valgus deformity.

radiographs and clinical results correlate poorly (Porter et al. 1974; Taylor et al. 1976; Copeland and Taylor 1979), indicating that other factors may contribute significantly to the poor results. Only two patients had radiographs which showed little or no articular damage; one was satisfied, but the other had considerable pain on the medial side of the elbow. In the absence of radiographic arthritic changes, we attribute the symptoms to tension on the medial ligament (Figs 6 to 9). A close association between instability and dissatisfaction with the procedure had been shown and we suggest that the inability of the medial ligament to withstand the loads exerted on it may be responsible for the deterioration of an initially good result, and further that this may be a direct consequence of increased forces produced by radial head excision.

We therefore suggest that a major cause of failure was mechanical, especially in the 10 cases that deteriorated after an initially good result. Biomechanical analysis indicates that when an object is lifted and the elbow flexed, there is considerable compression on both the humero-ulnar and humeroradial articulations, because the elbow flexors and the forearm muscles both cross the elbow joint. The forearm muscles are active in stabilising the wrist to allow the fingers to grasp. In the normal elbow a balance of forces exists between the radius and ulna which means that the ligaments are not in tension (Fig. 10). Following radial head excision, however, the axial load on the radius is transferred to the ulna, presumably via the interosseous membrane. There is then considerable tension on the medial ligament, to prevent a valgus deformity occurring, and this adds further to the humero-ulnar force (Fig. 11). Calculations based on even the diminished strength of rheumatoid patients show that the force, concentrated on the lateral edge of the coronoid process, may be several times the body weight (Amis et al. 1979b).

Joint space narrowing at the lateral edge of the coronoid process the predicted site of maximal loading.

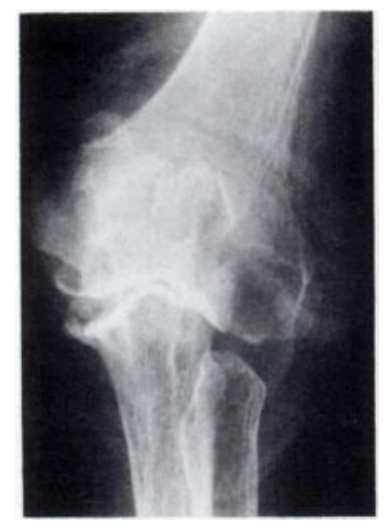

Fig. 12

Our results provide support for the biomechanical theory outlined above. Figure 12 illustrates secondary osteoarthritic effects particularly at the predicted site of maximal loading. Almost half the patients were satisfied with the result of the procedure and presumably in these the stabilising restraint of the medial ligament was adequate. Unfortunately, accurate prediction of the ability of the medial ligament to withstand the increased loading following radial head excision is not possible. 


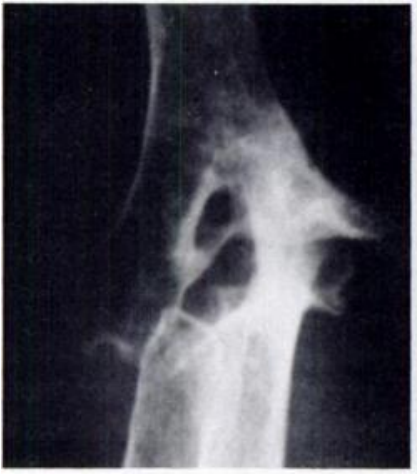

Fig. 13

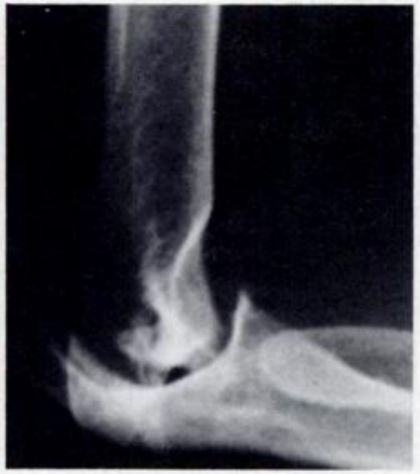

Fig. 14

This patient was delighted with the result of her operation. Her grossly unstable joint is subjected only to minimal loading as most of the tasks of daily living are carried out for her.

A grossly damaged unstable elbow is still compatible with an excellent result if there is a low level of activity (Figs 13 and 14). Two patients who claim to have

excellent results illustrated this point; both had pain only during the short period when they had to use a walking stick after a lower limb operation. Once the loading was discontinued their elbows became comfortable again (Amis et al. 1982).

Should painful instability develop after radial head excision, subsequent insertion of a radial head prosthesis to stabilise the joint may prove extremely difficult, either because the radius is malaligned on the capitellum, or because too much of the head and neck has been resected. Success of a resurfacing elbow arthroplasty is also compromised by the laxity of the medial ligament on which most resurfacing elbow arthroplasties largely rely for stability. We therefore suggest that, if possible, radial head replacement should be carried out at the time of resection (Mackay, Fitzgerald and Miller 1982) to avoid the adverse late effects of radial head excision demonstrated in this study.

We are very grateful to the staff of the Plastic Surgery Unit, Canniesburn Hospital, Glasgow, and the Orthopaedic Unit, Glasgow Royal Infirmary, for their assistance. We should also like to thank Professor D. Hamblen for his critical appraisal.

\section{REFERENCES}

Amis AA, Dowson D, Wright V, Miller JH. The derivation of elbow joint forces, and their relation to prosthesis design. J Med Eng Technol 1979a:3(5):229-34.

Amis AA, Hughes SJ, Miller JH, Wright V, Dowson D. Elbow joint forces in patients with rheumatoid arthritis. Rheumatol Rehabil $1979 \mathrm{~b} ; 18(4): 230-4$.

Amis AA, Hughes SJ, Miller JH, Wright V. A functional study of the rheumatoid elbow. Rheumatol Rehabil 1982:21(3):151-7.

Amis AA, Miller JH. The elbow. Clin Rheum Dis 1982;8(3):571-93.

Brattström H, Al Khudairy H. Synovectomy of the elbow in rheumatoid arthritis. Acta Orthop Scand 1975;46: $744-50$.

Copeland SA, Taylor JG. Synovectomy of the elbow in rheumatoid arthritis: the place of excision of the head of the radius. J Bone Joint Surg [Br] 1979:61-B:69-73.

Howard FM. Surgical aid for arthritis of the hand and elbow. J Int Coll Surg 1960:33:336-41.

Inglis AE, Ranawat CS, Straub LR. Synovectomy and débridement of the elbow in rheumatoid arthritis. J Bone Joint Surg [Am] 1971:53-A: $652-62$.

Laine V, Vainio K. Synovectomy of the elbow. In: Hijmans W, Paul WD, Herschel H, eds. Early synotectomy in rheumatoid arthritis. Amsterdam: Excerpta Medica Foundation, 1969:117-8.

Mackay I, Fitzgerald B, Miller JH. Silastic radial head prosthesis in rheumatoid arthritis. Acta Orthop Scand 1982:53:63-6.

McDougall A, White J. Subluxation of the inferior radio-ulnar joint complicating fracture of the radial head. J Bone Joint Surg [Br] 1957; 39-B: 278-87.

Marmor L. Surgery of the rheumatoid elbow. J Bone Joint Surg [ Am] 1972:54-A : 573-8.

Porter BB, Richardson C, Vainio K. Rheumatoid arthritis of the elbow: the results of synovectomy. J Bone Joint Surg [Br] 1974:56-B:427-37.

Stein H, Dickson RA, Bentley G. Rheumatoid arthritis of the elbow: pattern of joint involvement, and results of synovectomy with excision of the radial head. Ann Rheum Dis 1975;34(5):403-8.

Steinbrocker O, Traeger CH, Batterman RC. Therapeutic criteria in rheumatoid arthritis. JAMA 1949;140:659-62.

Swett PP. The present status of synovectomy. Am J Surg 1929; NS 6:807-10.

Taylor AR, Mukerjea SK, Rana NA. Excision of the head of the radius in rheumatoid arthritis. J Bone Joint Surg [Br] 1976:58-B:485-7.

Taylor TKF, O'Connor BT. The effect upon the inferior radio-ulnar joint of excision of the head of the radius in adults. J Bone Joint Surg [Br] 1964:46-B:83-8.

Torgerson WR, Leach RE. Synovectomy of the elbow in rheumatoid arthritis. J Bone Joint Surg [Am] 1970;52-A:371-5. 